\title{
HERITAGE DOCUMENTATION AND NATIONAL IDENTITY IN QATAR: CASE OF THE AL-ZAMAN HOUSE
}

\author{
S.B. GARBA, D. BOUSAA, G. FETAIS, A. ALHASSAN, H. BAKHIT, A. AL-DARWISH \& A. ALYAFEI \\ Department of Architecture and Urban Planning, College of Engineering, Qatar University Doha, Qatar.
}

\begin{abstract}
Qatar is a country with limited area and number of settlements. It has witnessed rapid development since the 1950s centred on Doha as a result of the exploitation of its petroleum resources. An outcome of the process was the lack of attention paid to conservation, leading to the loss of valuable heritage resources. Realization of the situation has led to concerted efforts to improve retention. Questions that arise from need for action include: what constitute heritage and how should documentation be carried out? This article contributes to answering these questions based on the documentation of the Al-Zaman house by a team from Qatar University. The article explores the potential of using affordable peripheral methods such as photo-modelling in documentation and examines the role that buildings constructed during periods of historical transition play in the construction of social identity. Analysis shows that such buildings capture the zeitgeist of an era and so form an important part of history and identity. It was also established that photo-modelling is inappropriate for use as a tool in documenting heavily decorated buildings that are in a state of dilapidation due to problems of clarity of textures and patterns. Keywords: heritage documentation, heritage resources, heritage use, history and identity, photomodelling, place making.
\end{abstract}

\section{INTRODUCTION}

Heritage plays an important role for societies as it links people with their history and provides them a sense of identity. Heritage resources are also recognized as having an economic value in view of their impact on tourism. In many countries, the late realization of the importance of heritage meant important resources were destroyed in the zeal for development. The increasing recognition of the value of heritage is leading many countries to focus on the preservation of available resources. Qatar is one of the countries where rapid development has led to the erosion of heritage resources. With massive revenues from petroleum resources, the country has witnessed a rapid process of development in what has been referred to as 'Oil Urbanism' [1]. The development process has seen Qatar integrated into the current globalization current and the evolution of a modern built environment, especially that of Doha. The process of modernization has, however, come with a price in terms of heritage preservation. Historic buildings, centres and districts became the victims as they were pulled down and replaced by modern buildings. The rapid disappearance of the historic built fabric of the country has recently become an issue of importance and led to a new focus on action to improve heritage retention. Action in respect of this new interest has also generated issues of developing capacity as well as experience in documentation activities with focus on the use of state-of-the-art technologies.

This article is a product of action to develop preservation capacity and promote experiencebuilding activities in Qatar and documentation activities focused on a heritage building, the Bait Al-Zaman located at Al-Ghanim in Doha. The article focuses on two questions that became central in the documentation process: what technique to use in documentation and 
what is the heritage value of the resource, in view of its being constructed during a period of cultural transition visible in changes in social patterns, practices and built form. The article presents the documentation process of the house with a focus on addressing the two questions. The next section presents a review on history, heritage and social identity. The third section presents the Al-Zaman house and its documentation process and output. The fourth section examines the role of buildings from transitional periods as heritage. The last section presents the conclusions and recommendations.

\section{HISTORY, HERITAGE AND SOCIAL IDENTITY}

\subsection{General review on history, heritage and social identity}

The recent emphasis on a socio-spatial approach to human settlements has led to an acknowledgement that they are socially produced through the actions of people. Knox and Pinch [2] point out that 'They are created by people, and they draw their character from the people who inhabit them.' The notion is also supported by the works of Lefebvre [3] on the production of space and Giddens [4] on the theory of structuration and its role in space creation. The production of human settlements is generally viewed as a ceaseless process that happens in time, with people in each period inheriting a fabric and traditions from the past, which constrains and shapes their action in the present and also directs the future path of development. At any particular period, people change and modify their environment to satisfy their needs, in reaction to social, economic, demographic, technological and cultural forces.

The production of heritage also occurs as part of the production of settlements and their built environments. As Carmona et al. [5] observe, 'a building or other element of the built environment of a given period and type tends to be a carrier of the zeitgeist or "spirit" of its time. Every city can therefore be read as a multi-layered "text", a narrative of signs and symbols ... the built environment becomes a biography of urban change.' All built elements in an urban area, therefore, have the potential to be classified as part of heritage resources and selected for preservation. This generates the question of which resource to select. Focus in selection is usually on buildings and areas with special architectural or historical-cultural interest. Ashworth [6] has provided a framework for the selection process. He points out that choice is usually dictated by significance tied to factors that include link to history, expression and embodiment of cultural spirit, practices and achievements, and contribution to memory and social identity among others The process of selection and interpretation also embodies the need to address how to retain such heritage, through either preservation or conservation.

\subsection{History, heritage and identity in Qatar}

Historical records point to Qatar being inhabited as far back as the 4th century. The modern history of the country is traceable to the 18th century, when the Al-Thani family became the rulers of the country. The desert nature of Qatar's environment precluded the establishment of many settlements because of the harsh environment. The most prominent old settlement was Bidda located on the coast, with economic activities focused on farming, herding and pasturing and maritime activities. In the 1800s, the rulers of Qatar relocated to the coast to establish Doha as a settlement adjacent to Bidda. Doha subsequently 
expanded and engulfed the settlement of Bidda. It was protected by a wall and became a British protectorate in 1887. It is now the capital of Qatar and its largest urban settlement. Rapid development in the country since the 1950s has seen the economy and physical pattern of settlements transform as a result of revenue from the exploitation of petroleum resources [7].

The concept of tradition and identity as expressed in architecture in Qatar is a product of practices that are shared within the region and with the Islamic world. Limitation in number of cities implied a limitation in urban and architectural heritage. Jaidah and Bourannane [8] have described the nature of the architectural heritage architecture that Qatar has. The form of the settlements, particularly cities, as they point out was strongly affected by the form of the Islamic city with its focus on mosque, suq, palace and private home, and its built elements generally reflected principles of Islamic architecture. They have classified heritage architecture, depending on influence, into two groups: coastal architecture, which was largely influenced by practices in Iran and is visible in Doha and other coastal cities such as Al-Khor and Al-Wakrah, and the architecture of interior areas largely influenced by practices from the Najd area of Saudi Arabia, and is visible in settlements such as Rayyan, Wajbah and Umm Slalal. The main heritage elements found are houses, military buildings and mosque. Jaidah and Bourannane [8] point out that cities and villages evolve as a result of the agglomeration of housing units (architecture of social value). Major influences include religion, privacy and the extended family, along with climatic considerations. The house as the main built element of a settlement's fabric is usually constructed with one wall facing the street and without decoration or opening. Where windows are located on these external walls, they are usually screened. The house is organized territorially into spaces of different degrees of privacy: private, semi-private, semi-public and public. The territorial delineation of housing spaces determines the level of access for family members, relatives and visitors depending on gender. Spaces are generally separated into male and female areas even among family members. The house would usually have four principal elements [8]: a courtyard which is the heart of family life, private spaces for domestic activities, spaces for social interaction with number varying according to status of family and functional rooms organized around the courtyards. Apart from kitchens and stores, all the spaces of the house are multipurpose, with use depending on time of year and climatic conditions. Most houses would also have terraces and veranda for shade and used in periods of extreme weather. Houses of rich people were decorated with gypsum depicting geometrical patterns or plant pictures [8].

Traditional construction relied on a limited pallet of available materials, complemented by imports from other sources. The main materials of construction are coral stones, limestone, mud, gypsum, mangrove poles, palm trunks and clay. Walls were usually constructed thick with limestone material, held together with packed mud, gravel and smaller stones. The walls were protected from erosion through the use of gypsum plaster. Mangrove poles bounded with ropes were used as lintel over doors and windows. Roofs were always flat and usually incorporated decorative elements. Mangrove beams were also used to support upper floors and roofs. These were usually overlaid with split bamboo poles and a palm mat. Roofs were made water tight through the use of layers of rammed earth.

The basic traditional approach to architecture and settlement construction and associated concept of tradition, heritage and identity was established in Qatar during the 19th and early 20th century periods, when many currently revered heritage buildings were built. The limited number of settlements meant that heritage buildings were found mainly in the four urban settlements of Doha, Wakra, Al-Khor and Umm Slalal. The heritage resources are currently 


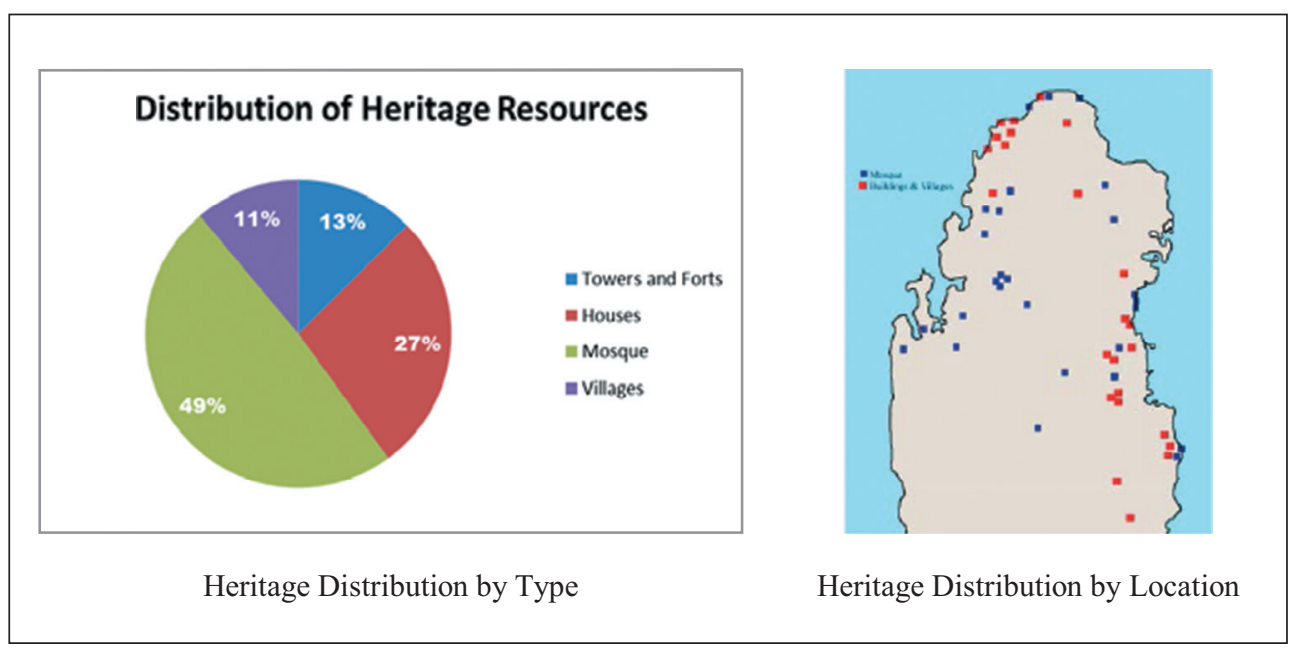

Figure 1: Distribution of heritage resources in Qatar by type.

managed by Qatar Museum that oversees the preservation work, day-to-day management as well as promotion of the heritage resources. The Museum Authority controls a total of 135 resources, which it has classified into mosque, buildings and villages. Figure 1 shows the distribution of the various heritage resources into the different classes and their location in the country.

\section{THE AL-ZAMAN HOUSE AND ITS DOCUMENTATION}

\subsection{Location and history of the Al-Zaman house}

The Al-Zaman house is located in Fareej Al-Ghanim in Old Doha (Fig. 2). Fareej Al-Ghanim is among the oldest neighbourhood of Doha and is named after the family that established it. The central location of the neighbourhood made it attractive for wealthy individuals and families, who formed the bulk of its residence during the 1950s to 1970s. The residents included several doctors, healers, businessmen and the first post-independence chairman of the Shoura Council of Qatar. The area was characterized by a dense fabric consisting of courtyard houses, sometimes of mixed use with shops below them. Most of the old traditional houses of the area have been demolished and replaced by medium rise buildings that are mostly commercial in orientation.

The Al-Zaman house is one of the very few important historic buildings in Al-Ghanim that has survived to the present, giving it historical importance and making its preservation an issue of priority. The house was built by Mr Faraj Al-Zaman in 1950. Figure 2 shows the house during its active period of use in the 1970s. At the time of construction, it was among the largest houses of Al-Ghanim and Old Doha. The form of the house mirrors the traditional courtyard house common in the Islamic world. The house consists of a large courtyard around which rooms are organized. In its original form, the house had a front entrance for families on the east elevation and one for males and visitors in the north elevation. The design of the house was influenced by environmental factors, particularly with regard to wind direction 


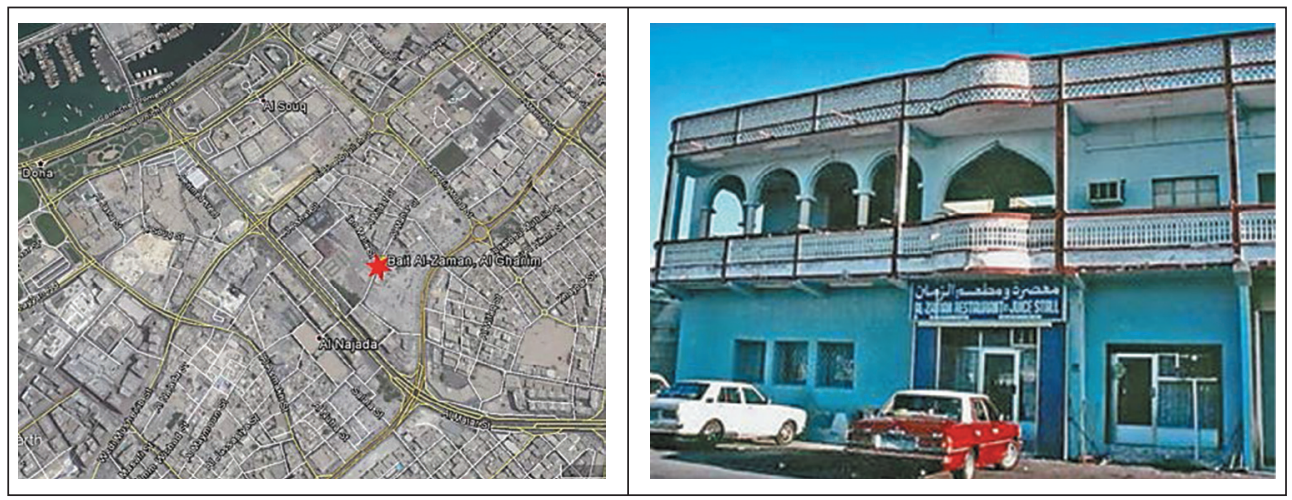

Figure 2: Location of Al-Zaman house and image in active use.

and sun penetration. Large terraces were provided on the upper floor in contrast with the use of Mushrabia in most of the city. The house transformed and increased in size as the family expanded. The owner of the house, Mr Al-Zaman, is believed to have imported labour and new materials, such as steel and concrete, to build the house. The architecture of Al-Zaman house also went beyond Qatari architecture, and incorporated architectural features from different cities of India, Iran, Oman and other Gulf areas. The Al-Zaman family lived in the house up to the 1970s, after which they moved to a new more modern area in tune with modernizing trend of developments in Qatar during the period. Since leaving the house, it appears to have been occupied by low-income labourers, who repartitioned most rooms, during which the condition of the house gradually deteriorated.

\subsection{Documentation process, methods and output}

The documentation process of Al-Zaman house was carried out in multiple steps following established practice in the literature [9]. The steps include selection and initial studies, data collection and recording, analysis of data and output of documentation process and information sharing. The building for documentation was suggested by Qatar Museum. The building was under the custodianship of the museum that wanted to initiate action for its restoration but was limited by the complete lack of representational information to facilitate evaluation and conservation action. The lack of representational information was complicated by the fact that the building had complex geometry and angles that made resolution of its shape and form problematic. At the start of the project the team opted to try photo-modelling as an affordable low-cost approach to documentation. The team's initial step was to undertake an assessment and historical study of the house. The team made several visits to establish the spaces of the house, their configuration as well as materials and construction system used. The initial studies pointed to the dilapidated situation of the house with its structure disintegrating and collapsing in certain parts. Once the initial studies were completed, the team moved into detailed fieldwork. This involved three tasks. The first was a detailed photographic survey of the house. This involved getting pictures of all parts of the house from both interior and exterior perspectives. The photos were to serve as part documentation of the house and also to be used in photo-modelling. The second task was a detailed video documentary of the house. The aim was to have a movie of the house with historical narrations about its function 
and use. This activity was carried out with the facilitation of Mr Al-Zaman, who contributed in narrating the history of the house. The last task was detailed measurements of the house. This involved taking both internal and external measurements along with dimensions of all embedded components. This was designed to facilitate the production of accurate twodimensional representational drawings.

At the end of the field work, the team moved to the stage of analysis and photo-modelling. Two cameras were used in photo documentation - a Sony Alpha camera and a Cannon EOS 50D camera - with the aim of using their output for modelling. The two cameras were calibrated using information from the software providers. Attempts to model the building using both manual line and point methods and automatic recognition methods failed for two reasons: first the level of dilapidation of the house meant patterns were not uniform on facades, making it difficult for the software to recognize and digitize elements. Using manual tracing methods also failed, as the complexity of the building, state of dilapidation and lack of structural integrity of elements made it difficult for the photo-modeller to cross-reference images and to generate a three-dimensional model of the building.

With failure in the use of photo-modelling, the team had to resort to use of field measurements, digital image and photo analysis to construct representational drawings of the house. Analysis of digital imagery provided an avenue to determine the various angles of the planes that made up the house, while field measurements enabled the reconstruction of all space of the house room by room to arrive at a final accurate representational plan of the house. Once the plan was finished, the team moved on to generate other drawings, including elevations and sections and also a digital model of the house.

\subsection{Assessment of the state of Al-Zaman house}

Having documented the house, the team moved to the stage of assessing the state of the heritage resources. As pointed out earlier, at the point of starting the project, the Al-Zaman house was already in a state of dilapidation (Fig. 3). The house had been unoccupied for a long time. The open area around the building was being used as a parking lot by cars and lorries. The environment of the house was littered and the lack of paving meant that the house was exposed to erosion at its lower level. The house also suffered from problems of structural integrity; parts of the roof had collapsed and caved in, and balconies and parapets were broken. Some of the rooms were used for junk storage, which in some cases limited access. Other noticeable aspects of the dilapidation include broken decorative elements, collapsing walls, particular in the interior courtyard, ceiling damage and, in some rooms, collapse of the ceiling, and collapsed balconies and handrails. The house was also experiencing development pressure as a result of rapidity of building activity in its vicinity. The state of dilapidation pointed to the need for urgent action to stabilize the building and proceed with action to conserve. As at the time of finishing the documentation exercise in September 2015, Qatar Museum had already initiated action to stabilize the structure. The team in its final report recommended conservation of the house, with focus on rehabilitating it for use, possibly, as a museum of transitional culture and also as a tourist centre.

\subsection{Products of the documentation exercise}

The documentation of the Al-Zaman house led to the production of two principal products or output: representational drawings of the house in its pre-dilapidation state, photo and video 


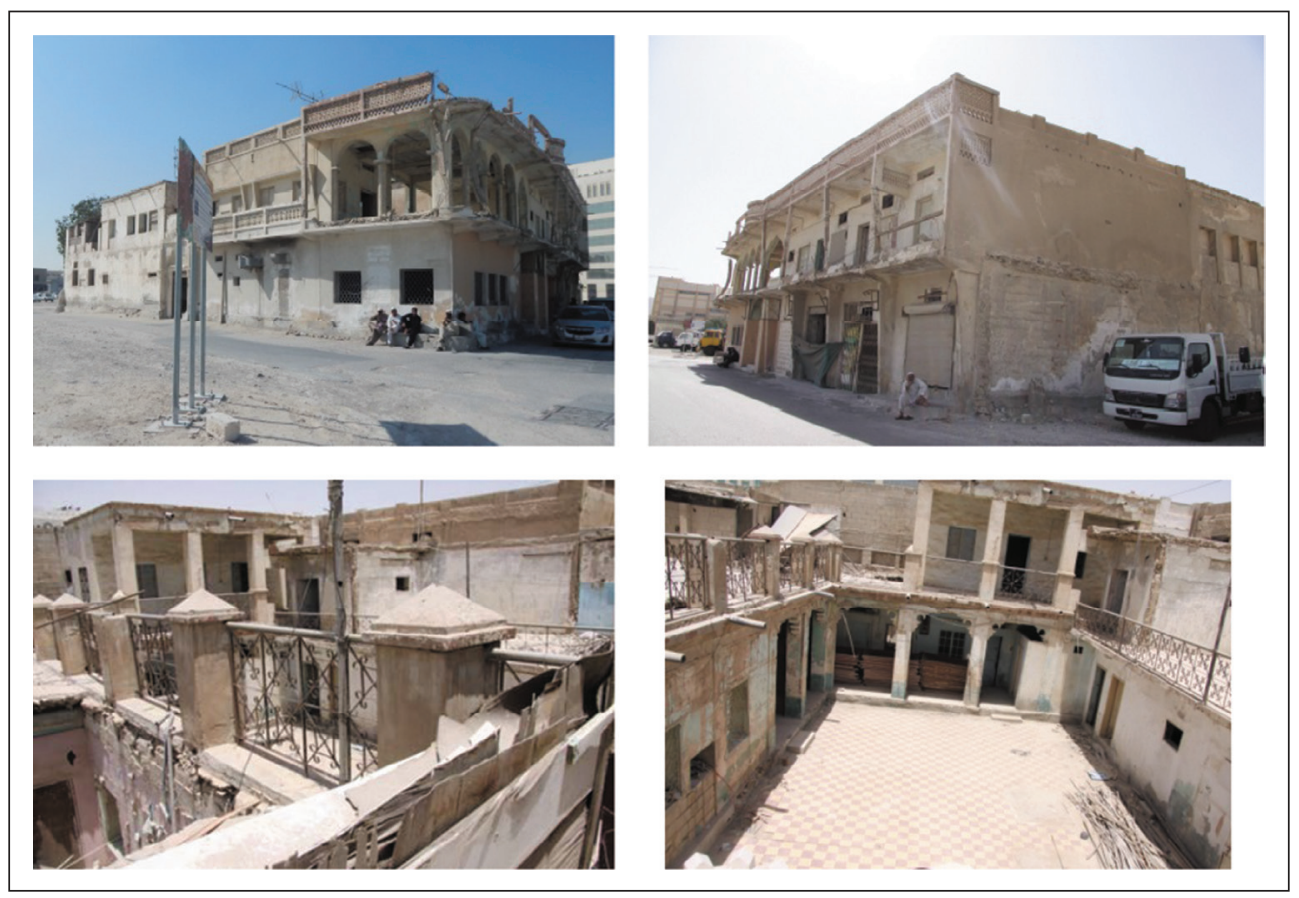

Figure 3: Current state of Al-Zaman house.

documentary of the house. The team produce scaled drawings of the house that included plans, sections and elevations (Fig. 4) along with a computer-generated three-dimensional model. The scaled drawings capture the structure and form of the house and provide a platform for action in the conservation of the house. The team produced a video documentary that captured the owner of the house, Sheikh Al-Zaman, being interviewed both in an office setting and also at the Al-Zaman house, where he explains its history and use. This film represents a valuable resource for the promotion of the house as heritage once it is restored. The team also has a large collection of photos of the house. The photos adequately capture all aspects of the house, including its materials, construction system, decoration and views of the house.

\section{TRANSITIONAL BUILDINGS, NATIONAL HERITAGE AND IDENTITY IN QATAR- A DISCUSSION}

The article started with the aim of exploring the feasibility of using peripheral low-cost methods such as photo-modelling for heritage documentation and of the value of Bait Al-Zaman, a transitional period building, as heritage. With regard to the issue of documentation method, the initial focus on use of photo-modelling failed, as pointed out earlier, due to the complexity of the house and its state of dilapidation. This forced the team to use manual techniques to produce final representational drawings. The team's final drawing accurately captures the house in both two-dimensional and three-dimensional form. The drawings and other products of documentation provide a platform for progression in action to conserve the house. 


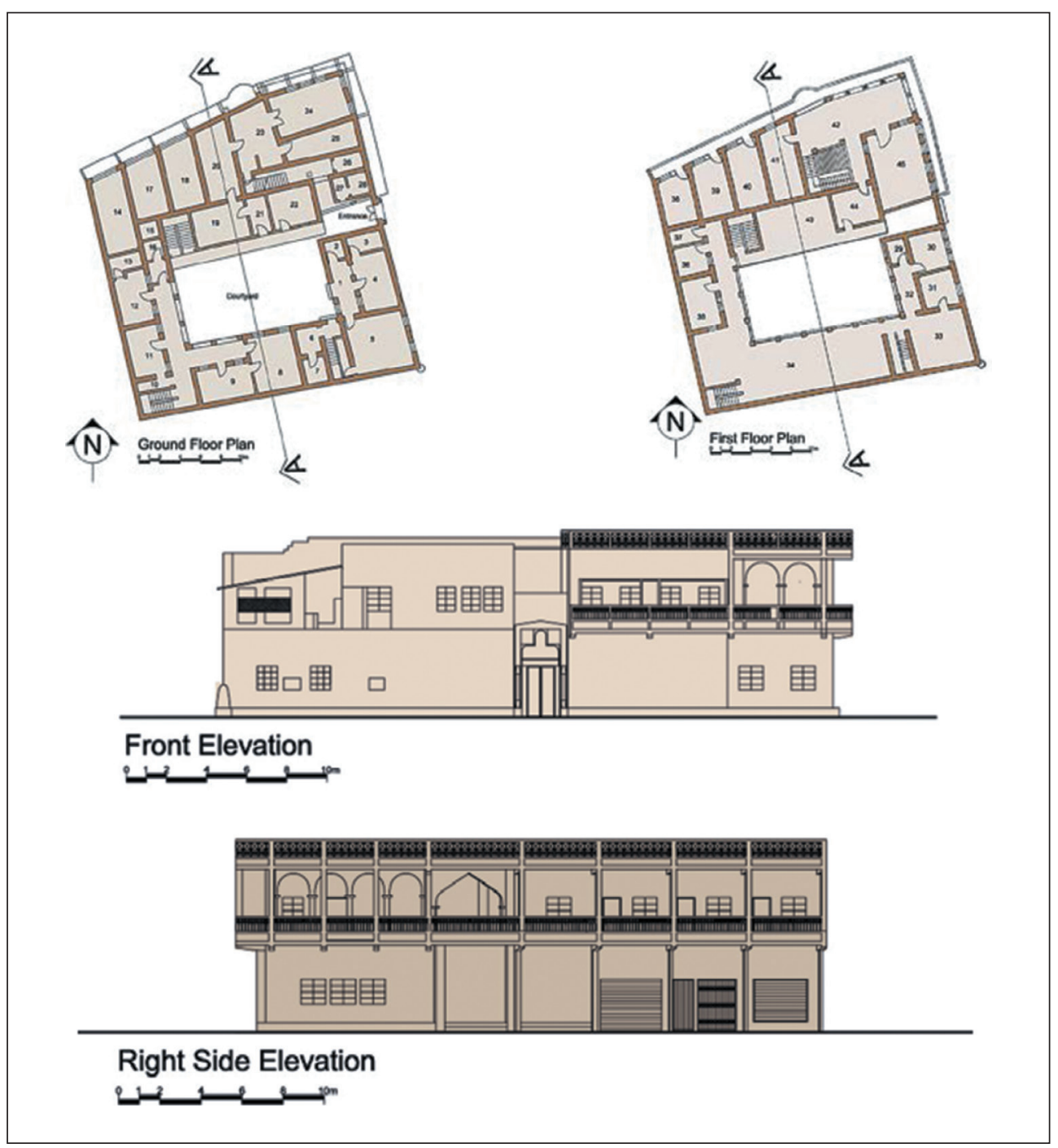

Figure 4: Documentation drawings of the Al-Zaman house.

With regard to the value of Al-Zaman house as heritage, discussion has to be placed in the context of historical change and the availability of adequate cultural resources to educate the people of the country in their history and identity. The buildings and cities we produce play a significant role in defining our identity both from a social and spatial perspective. Meaning and identity in this respect is not static, but rather evolves in tune with historical change. For the people of Qatar, historical evolution has led to a clear conception of appropriate traditional architecture that has prevailed up to the middle of the last century. The 1950s, however, witnessed the introduction of a petroleum economy and the introduction of new construction materials and their adoption and adaptation to traditional construction practices to create a 
hybrid transitional construction style that shares the advantage of both modern and traditional construction systems. These transitional buildings are evident from the use of masonry blocks and concrete in parts of the building, usually additions, as well as maintaining the core traditional shell with its traditional construction elements but uniting both through the use of decoration that includes protrusions and recesses, as well as flowery decorations. There is also always an attempt in these buildings to marry both construction forms through geometric ordering with roots in tradition.

Since the 1970s, however, the country has witnessed a rapid process of development activity that has resulted in the evolution of an eclectic urban form. The process has particularly become rapid in recent years, as signature modern and postmodern architecture seem to characterize major urban developments. Most of these are private sector driven and more concerned with marketing than with defining an architectural and social identity for Doha. The market-driven nature of development is a product of desire for association with modernization and globalization as a means to expand the appeal of products. Parallel to this movement and as a counterbalance to it is a neo-traditional movement and trend found in government buildings. The trend appears to be pushing for more historical and traditional forms as a way of rooting society in its past. It is the neo-traditional movement, which is growing, that is pushing for a re-assessment of the approach to heritage and for action towards conservation. The push is however coming too late, as areas with significant resources have already been transformed, leaving very few resources to conserve.

Based on earlier examination of the concept of heritage, it was pointed out that human production of space and built environment is a ceaseless process with each period read as part of a multi-layered text of signs and symbols reflecting the biography of urban change. Each period therefore captures a part of the diversity of a city's time structure. Defining what constitutes heritage involves selecting from the multitude of the built products of each period, as a reflection of the collective memory and identity of a place and its people. In Qatar, the rapid process of development and lack of concerted efforts during the initial phase of development has meant that limited amount of heritage resources have survived that can serve as the focus of conservation. The Al-Zaman house is among the few old buildings that have survived in the vicinity of its location at Al-Ghanim area. The neighbourhood has since transformed from its traditional roots to more of a commercial district characterized by medium rise large developments. The association of the house with a prominent family that has connection to the history of the neighbourhood and played important roles in its development also gives the house value as a heritage resource. The Al-Zaman house is also distinctively reflective of a unique period of Qatari development. The house was constructed at a time when the country was witnessing the first wave of transition from a traditional economy and lifestyle to a modern society. The house captures the spirit of the era in its integration of construction materials and methods from both historical and emerging eras. The house was also a prominent landmark in its time. All of these, it is believed, combine to justify its classification as heritage and also its documentation for preservation. Architecturally, the building also reflects the tendency to integrate new materials and construction with a traditional courtyard residential building to create a hybrid form that the research team labels as 'transitional' in reflection of its situation in an in-between space of traditional and contemporary practices. Considering all of the above, the above importance of the building as heritage resource is evident. This importance was reinforced by the decision of Qatar Museum to select and recommend the Al-Zaman house for documentation. 


\section{CONCLUSION AND RECOMMENDATIONS}

The study presents experience from the documentation of Al-Zaman house in Doha, Qatar, with focus on exploring the use of low-cost affordable techniques such as PhotoModeler in documentation and examining the role of transitional period houses as heritage. Based on historical study and analysis of the value of the house, it is believed that the house should be classified as heritage and can contribute to national heritage and identity in Qatar. Regarding the documentation of the house, the team's experience points to difficulties of using photomodelling for buildings that are in a state of extreme dilapidation. It is therefore recommended that in documenting such category of buildings, the use of such methods be avoided in favour of either traditional field methods or the use of high-end system such as digital scanning.

Regarding the documented building, assessment shows that it is in a dilapidated state and is still deteriorating. The team would like to recommend the initiation of urgent action to stabilize the structure and clear it of all the materials that have been stored in it. Based on the documentation exercise, the team is of the opinion that the house can be reconstructed using materials that match what was previously used. The team would also recommend that the house after conservation should be configured as a museum and tourist centre with focus on display of artefact and visual images of lifestyle during the transitional phase of the country's development.

\section{ACKNOWLEDGEMENT}

This conference paper was made possible by an UREP grant \# 16-048-2-007 from the Qatar National Research Fund (a member of Qatar foundation). The statements made herein are solely the responsibility of the authors.

\section{REFERENCES}

[1] Rizzo, A., Metro Doha city profile. Cities, 31, pp. 533-543, 2013. DOI: 10.1016/j. cities.2011.11.011

[2] Knox, P. \& Pinch, S., Urban Social Geography: An Introduction, Prentice Hall: Harlow, England, p. 8, 2000.

[3] Lefebvre, H., The Production of Space, Blackwell: Oxford, 1991.

[4] Giddens, A., The Constitution of Society: Outline of the Theory of Structuration, Polity Press: Cambridge, 1981.

[5] Carmona, M., Heath, T., Oc, T. \& Tiesdell, S., Public Spaces Urban Spaces: The Dimensions of Urban Design, Architectural Press: Oxford, p. 196, 2003.

[6] Ashworth, G.J., Conservation as preservation or as heritage: two paradigms two answers. Designing Cities: Critical Readings in Urban Design, ed. A. Cuthbert, Blackwell Publishing: Oxford, pp. 244-246, 2003.

[7] Salama, A.M. \& Wiedmann, F., Demystifying Doha: On Architecture and Urbanism in an Emerging City, Ashgate Publishers: Surrey, 2013.

[8] Jaidah I., \& Bourannane, M., The History of Qatari Architecture 1800-1950, Skira, Milano, Italy, 2010.

[9] Lattellier, R., Recording, Documentation, and Information Management for the Conservation of Heritage Places, The Getty Conservation Institute: Los Angeles, p. 26, 2007. 